\title{
Partnering With Massage Therapists to Communicate Information on Reducing the Risk of Skin Cancer Among Clients: Longitudinal Study
}

Lois Loescher ${ }^{1}, \mathrm{PhD}$, FAAN; Kelly Heslin ${ }^{1}, \mathrm{MPH}, \mathrm{CHES}$; Graciela Silva ${ }^{1}, \mathrm{PhD}, \mathrm{MPH}$; Myra Muramoto ${ }^{2}, \mathrm{MD}, \mathrm{MPH}$

${ }^{1}$ College of Nursing, University of Arizona, Tucson, AZ, United States

${ }^{2}$ Colleges of Medicine and Public Health, University of Arizona, Tucson, AZ, United States

Corresponding Author:

Lois Loescher, PhD, FAAN

College of Nursing

University of Arizona

1305 N Martin Ave

P.O. Box 210203

Tucson, AZ, 85721

United States

Phone: 15206266169

Email: loescher@arizona.edu

\section{Abstract}

Background: Skin cancer affects millions of Americans and is an important focus of disease prevention efforts. Partnering with non-health care practitioners such as massage therapists (MTs) can reduce the risk of skin cancer. MTs see clients' skin on a regular basis, which can allow MTs to initiate "helping conversations" (ie, brief behavioral interventions aimed at reducing the risk of skin cancer).

Objective: The purpose of this study was to evaluate (1) the feasibility of recruiting, enrolling, and retaining Arizona MTs in an online electronic training (e-training) and (2) the preliminary efficacy of e-training on knowledge, attitudes/beliefs, and practice of risk reduction for skin cancer. We explored MTs' ability to assess suspicious skin lesions.

Methods: We adapted the existing educational content on skin cancer for applicability to MTs and strategies from previous research on helping conversations. We assessed the feasibility of providing such e-training, using Research Electronic Data Capture (REDCap) tools for data capture. We assessed the preliminary efficacy using established self-report surveys at baseline, immediately post training, and at 3 and 6 months post training.

Results: A total of 95 participants enrolled in the study, of which 77\% (73/95) completed the assessments at 6 months (overall attrition=23\%). Project satisfaction and e-training acceptability were high. Knowledge, personal behaviors (skin self-examination, clinical skin examination, sun protection frequency), and practice attitudes (appropriateness and comfort with client-focused communication) of risk reduction for skin cancer improved significantly and were sustained throughout the study.

Conclusions: The e-training was feasible and could be delivered online successfully to MTs. Participants were highly satisfied with and accepting of the e-training. As such, e-training has potential as an intervention in larger trials with MTs for reducing the risk of skin cancer.

International Registered Report Identifier (IRRID): RR2-10.2196/13480

(JMIR Form Res 2020;4(11):e21309) doi: 10.2196/21309

\section{KEYWORDS}

cancer prevention; skin cancer; e-training; electronic intervention; massage therapists

\section{Introduction}

Skin cancer, the most common cancer in the United States, poses a serious public health burden. Over 5.4 million nonmelanoma skin cancers are treated annually [1]. The incidence of melanoma, the most fatal form of skin cancer, increases by about $3 \%$ each year among persons aged $>50$ years [2]. Skin cancer costs exceed billions of dollars annually [3]. 
Fortunately, the skin cancer burden can be abated through primary prevention and early detection.

Protecting the skin from ultraviolet radiation reduces the risk of skin cancer [4,5]. Recommended primary prevention behaviors are as follows: avoid prolonged sun exposure during peak intensity, cover the skin with tightly woven protective clothing (eg, long sleeves/pants, wide-brimmed hats, and sunglasses), seek shade, apply/reapply sunscreen, and avoid all kinds of intentional tanning [6]. Early skin cancer detection decreases potential morbidity, mortality, and cost [2,3] and can be carried out with viewable skin assessment (VSA) by health professionals or with skin self-examination (SSE) by consumers. Skin lesions can be assessed using several approaches, one of which is the common asymmetry, border, color, diameter, evolving (ABCDE) rule [7].

One approach for delivering risk-reducing information on skin cancer is a structured "helping conversation," a person-centered communication technique that emphasizes on active listening and motivational communication to encourage healthy behavior change [8]. A helping conversation consists of 4 steps: awareness, understanding, helping, and relating [9]. Helping conversations are context-specific and thus cost-effective and time efficient [8]; they have been used for other preventive behaviors $[8,10]$ but not in the context of risk reduction for skin cancer.

The Surgeon General's Call to Action to Prevent Skin Cancer [6] endorses community partnerships for reducing the risk of skin cancer. Community partners who can implement helping conversations about reducing the risk of skin cancer include massage therapists (MTs). Compared to primary care providers or dermatologists, MTs are more likely to have repeated and longer appointments that are oriented toward health promotion [11-13], thereby providing greater opportunities for helping conversations. MTs uniquely access most of a client's skin, allowing VSA. Approximately 385,000 MTs and MT students nationwide, provided with training, have the potential to engage in helping conversations [14].

Some MTs receive education on skin cancer during primary training (60\%) and continuing education (25\%) [15]; however, the content, duration, and source of this education vary. The few existing skin cancer-focused in-person workshops and 1 online course do not include training for client-focused communication on reducing the risk of skin cancer [15]. There is a need to assess the feasibility of providing such training to MTs, particularly considering the popular press stories of their involvement in early detection [15-17].

Our goal was to develop and evaluate the feasibility of delivering online e-training on reducing the risk of skin cancer, to MTs within the context of a helping conversation. Specific aims of this study were as follows:

1. Assess e-training feasibility, namely, facilitators and barriers to recruitment and enrollment, intervention completion and acceptability, and client acceptability of helping conversations.

2. Analyze the preliminary efficacy of e-training preliminary efficacy in terms of knowledge, personal/practice-based attitudes/beliefs, and practice factors of risk reduction for skin cancer, from baseline to immediately post training and 3 and 6 months post training.

3. Explore the assessment of suspicious versus nonsuspicious skin lesions.

\section{Methods}

The University of Arizona Institutional Review Board approved this study. Data collection was performed between July 1, 2018, and April 1, 2020. Data analysis was completed on April 27, 2020. The study had 3 phases. In phase 1 , we developed e-training content, assessments, and technology. In phase 2, we conducted a feasibility study (recruitment, screening, and enrollment; e-training implementation; and assessment of the main variables at 4 time points). In phase 3 , we conducted data analysis and interpretation. We have previously published the protocol for this study [9], which is briefly summarized below.

\section{Conceptual Framework}

Social cognitive theory (SCT) posits that individuals learn and maintain new behaviors through reciprocal interaction of person, environment, and behavior [18]. This study was guided by 4 SCT constructs: (1) reciprocal interaction of MTs, their external social contexts, and behavioral responses to the e-training; (2) behavioral capability to have a helping conversation; (3) observational learning from e-training vignettes; and (4) self-efficacy for mastery of knowledge and practice changes.

\section{Study Population}

We initially recruited a single cohort of MTs through professional networking, social media posts (on Facebook), flyer postings at MT practices, peer referral, massage school listservs, and online newsletter postings. Eligibility criteria were as follows: age $\geq 21$ years, licensed in Arizona, practicing for at least 3 years, averaging at least 5 clients per week, and internet access. Eligible MTs provided informed consent prior to enrollment. Participants received US \$200 for the 6 months of participation and continuing education credit units.

\section{Sample Size}

Sample size estimations were based on prior studies of skin cancer training for medical students [19] and our research on helping conversations about tobacco cessation with MTs [10]. A repeated measures power analysis for proportions (effect size $16 \%$ at pretest and $51 \%$ at posttest) indicated that 40 MTs would be needed $(\alpha=.05 ; \beta=.9)$. The reported attrition from online trainings ranged from $20 \%$ to $80 \%$ [20,21]. Enrolling 80 MTs would allow for attrition and reasonable estimation of sample size and recruitment and attrition in a future trial [19]. Power analyses were conducted using PASS software (version 12) [22].

\section{Intervention}

The e-training was built on previously developed skin cancer prevention e-training [23] and established competencies of helping conversations [8]. Participants sequentially completed 6 asynchronous, self-paced modules: introduction, awareness, understanding, helping, relating, and closing. After the modules, they completed 5 simulations of MT-client encounters, reflecting 
helping conversations that could occur during a 60-minute, full-body massage.

\section{Measures}

Using Research Electronic Data Capture (REDCap) tools hosted at the University of Arizona [24,25], we collected data at 4 time points: baseline (at enrollment), 1 week post training, 3 months post training, and 6 months post training. REDCap is a secure, web-based software platform for supporting data capture for research studies, providing (1) an intuitive interface for validated data capture, (2) audit trails for tracking data manipulation and exporting, (3) automated export procedures for seamless data download to common statistical packages, and (4) procedures for data integration and interoperability with external sources.

To assess e-training feasibility, we maintained detailed recruitment and enrollment records, coding how each potential participant learned of the study. This allowed us to determine the participant yield from each strategy. We used REDCap reporting capabilities to assess e-training completion rates.

Participants responded to 8 e-training satisfaction items (5-point scale, completely unsatisfied $=1$ to completely satisfied $=5$ ). To assess acceptability of the helping conversations of participating MTs, clients completed a 10-item anonymous survey accessible via a quick response (QR) code embedded in the flyers posted at the participating MTs' practices. If a helping conversation occurred, then the client selected topics mentioned by the MT, along with their recommendations (5-point scale, strongly disagree $=1$ to strongly agree $=5$ ). Clients received a US $\$ 5$ gift card for participating.

To assess the preliminary efficacy of e-training, we measured general knowledge on skin cancer with 16 multiple-choice items adapted from previous research (scored as correct or incorrect) [26] and 1 item measuring knowledge of the ABCDE rule (scored as correct or incorrect). We measured self-efficacy using a 10-item general self-efficacy scale [27] (4-point scale, not at all true $=1$ to exactly true $=4$; total score is calculated by finding the sum of all items and ranges between 10 and 40 with a higher score indicating more self-efficacy). Personal beliefs and attitudes were measured with 1 item for assessing participants' perceived probability of getting skin cancer in the future (scored from $0 \%-100 \%$ ), 5 items for appropriateness of including information about reducing the risk of skin cancer in client interactions, and 3 items about their own comfort with and confidence during those interactions (5-point scale, strongly disagree $=1$ to strongly agree $=5$ ).

We measured participants' personal behaviors of skin cancer risk reduction with 5 items pertaining to the frequency of sun protection behaviors (5-point scale, never $=1$ to always $=5$ ) and 1 item each for tanning booth visitation (5-point scale, in the past month $=1$ to never=5), $\operatorname{SSE}$ (5-point scale, never=1 to more than once a month=5), VSA (5-point scale, never=1 to more than once a month $=5$ ), and clinical skin examination (5-point scale, never $=1$ to more than once monthly=5).

Using a 29-item questionnaire on case-based image assessment adapted from a medical continuing education training [28], we measured participants' ability to assess skin lesions. Participants viewed photos of skin lesions accompanied by brief case descriptions, scoring each image as suspicious or not suspicious (scored as correct or incorrect).

We invited participants based in Tucson, Arizona, $(n=10)$ to an in-person posttraining debriefing. We asked them about their overall e-training experience (key takeaways, application in practice, and confidence regarding helping conversations). We asked whether they had noticed any suspicious lesions on a client's skin during study participation and how we could improve the e-training. Study personnel took detailed notes and compiled the comments.

\section{Statistical Analysis}

We assessed all data for missing and outlier values, deleting missing values listwise and double-checking and verifying outlier data. To describe demographic variables, we computed frequencies and means. We also computed individual composite scores, which summed the average answer value for each item of each of the assessment questionnaires: self-efficacy, personal beliefs and attitudes, and frequency of sun protection behavior.

We scored general skin cancer knowledge questions as percentages of correct or incorrect answers and computed mean scores for questions with continuous answers, such as perceived probability of getting skin cancer. We computed the percentages of correct and incorrect answers for image assessments. Using repeated measures analysis of variance, we evaluated longitudinal differences in composite scores for each of the measures; percentage of correct answers; and continuous variables at baseline, immediately post training, and at 3 and 6 months post training. We used Intercooled Stata, version 15 (Stata Corp), and applied a significance level of .05 for all statistical tests.

\section{Results}

A total of 95 participants enrolled in the study: $77 \%$ (73/95) completed all assessments at 6 months. The final sample had a mean age of 46 years; was predominantly female $(93 \%)$, non-Hispanic or Latino (89\%), and White $(83 \%)$; worked part-time; and saw <11 new or returning clients per week (Table 1). There were no major differences in the demographic characteristics between participants who completed the e-training and those who completed the training and all assessments. 
Table 1. Demographic characteristics of the sample (N=73).

\begin{tabular}{|c|c|}
\hline Characteristics & Values \\
\hline Age in years, mean (SD) & $46(12)$ \\
\hline Hours worked per week, mean (SD) & $23(10)$ \\
\hline Number of new clients per week, mean (SD) & $9(9)$ \\
\hline Number of returning clients per week, mean (SD) & $11(7)$ \\
\hline \multicolumn{2}{|l|}{ Gender, $\mathbf{n}(\%)$} \\
\hline Male & $5(7)$ \\
\hline Female & $68(93)$ \\
\hline \multicolumn{2}{|l|}{ Ethnicity, n (\%) } \\
\hline Hispanic or Latino & $8(11)$ \\
\hline Non-Hispanic or Latino & $64(89)$ \\
\hline Prefer not to answer & $0(0)$ \\
\hline \multicolumn{2}{|l|}{ Race, $n(\%)$} \\
\hline American Indian or Alaskan Native & $4(6)$ \\
\hline Asian & $3(4)$ \\
\hline Black or African American & $4(6)$ \\
\hline Native Hawaiian or other Pacific Island & $1(1)$ \\
\hline White & $60(83)$ \\
\hline Prefer not to answer & $0(0)$ \\
\hline Personal history of skin cancer $=$ yes, $\mathrm{n}(\%)$ & $7(9)$ \\
\hline Family history of skin cancer $=$ yes, $\mathrm{n}(\%)$ & $40(55)$ \\
\hline
\end{tabular}

During recruitment, 225 MTs requested study information. Out those, $170(68 \%)$ underwent eligibility screening, and 95 (42\%) were enrolled (see Figure 1 for recruitment yield). Overall attrition following enrollment was 23\% (Figure 1). Participant acceptability of the e-training and study procedures are shown in Table 2.

A total of 57 clients reported visits with 9 participating MTs (who did not vary in demographics from the overall sample). Clients reported 55 helping conversations, primarily focusing on skin cancer prevention. Conversations mentioned the topics of sunscreen (91\%), protective clothing (76\%), and wide-brimmed hats $(74 \%)$. Clients agreed that MTs appropriately initiated the helping conversation (mean 4.41, SD 0.92). Clients were accepting of questions by their MT about sun safety and sun protection behaviors (mean 4.09, SD 1.35), SSE behaviors (mean 3.78, SD 1.65), suggestions regarding skin cancer prevention (mean 4.35, SD 0.99), and shared information about skin cancer prevention (mean 4.45, SD 0.97). Clients were less accepting of queries about marks on their skin (mean 2.30, SD 2.33) and referral to a dermatologist (mean 2.92, SD 2.26). 
Figure 1. CONSORT (Consolidated Standards of Reporting Trials) flow diagram.

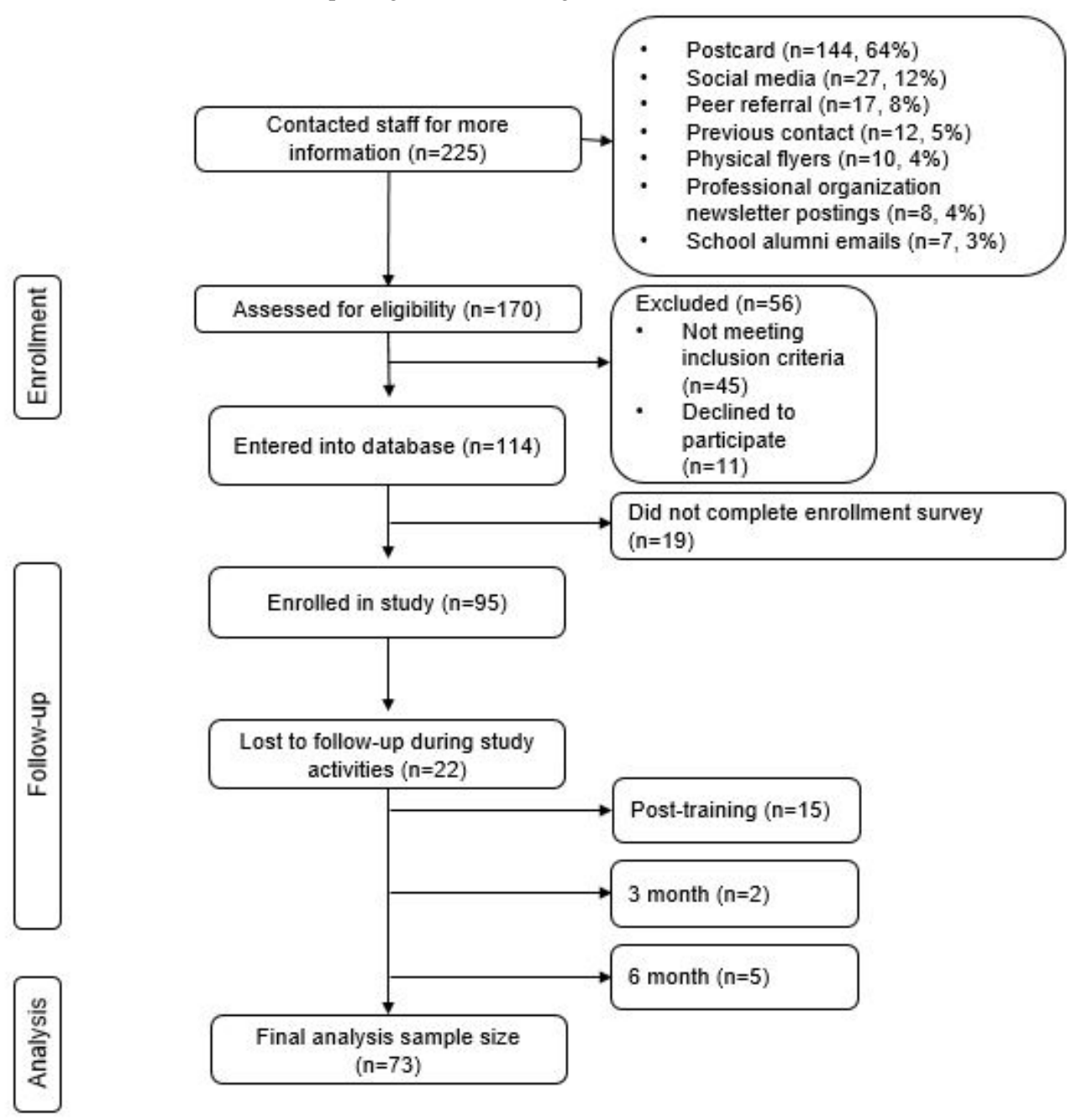


Table 2. Project satisfaction and attitudes toward training ( $\mathrm{N}=73)$.

\begin{tabular}{|c|c|}
\hline Criteria & Values, mean (SD) \\
\hline \multicolumn{2}{|l|}{ Project satisfaction $(1=$ completely unsatisfied; $5=$ completely satisfied $)(\mathbf{N}=\mathbf{7 3})$} \\
\hline Overall, how satisfied were you with participation in this project? & $4.4886(0.99)$ \\
\hline How would you rate the quality of the information you received as part of this project? & $4.4953(0.62)$ \\
\hline How would you rate the value of this project based on the amount of time you participated? & $4.5022(0.84)$ \\
\hline How responsive were study staff to your questions or concerns about the project? & $4.5092(0.69)$ \\
\hline How likely are you to continue using the skin cancer risk reduction knowledge you learned? & $4.5024(0.52)$ \\
\hline How likely are you to continue to use the helping conversation skills you learned? & $4.4955(0.67)$ \\
\hline How likely is it that you would recommend this training to a colleague? & $4.5024(0.90)$ \\
\hline Overall, how satisfied were you with the training? & $4.47(0.65)$ \\
\hline Scale mean & $4.51(0.01)$ \\
\hline \multicolumn{2}{|l|}{ Attitudes toward training $(1=$ strongly disagree; $5=$ strongly agree $)(\mathrm{N}=81)$} \\
\hline I would take this training only if continuing education units were offered. & $2.7(1.12)$ \\
\hline The time commitment required for the training was realistic. & $4.31(0.75)$ \\
\hline The training met my personal expectations. & $4.12(0.84)$ \\
\hline I would take this training without receiving an incentive. & $3.73(0.99)$ \\
\hline I learned more than I knew before about skin cancer risk reduction. & $4.14(0.96)$ \\
\hline I trusted the information I received from the training. & $4.49(0.74)$ \\
\hline The content of the training was useful for my daily life. & $4.43(0.78)$ \\
\hline The training helped build my self-confidence. & $3.9(0.96)$ \\
\hline I would recommend this training to others. & $4.38(0.81)$ \\
\hline
\end{tabular}

During the debriefing session, participants stated that the e-training component of the helping conversation was the easiest to remember. Helping conversations were new knowledge to most participants, encouraging communication skills that were not emphasized during their MT education. A common theme was posttraining confidence in discussing skin cancer risk reduction. Participants also found that their existing clients were more accepting of conversations than new clients. The most common conversation topics were prevention-oriented, such as reducing sun exposure; these conversations often started with variations of the example phrases provided in the e-training (eg, "what do you do to protect yourself from the sun?"). Moreover, 2 MTs reported mentioning suspicious lesions to clients, which were later diagnosed as skin cancers by a dermatologist.

Preliminary efficacy results for knowledge, personal and practice beliefs, and behaviors are shown in Table 3 along with the exploratory findings for the case-based image assessment. During the in-person debriefing session, participants commented that they would have preferred more examples of suspicious skin lesions and correct answers to each case. Participants felt there was no harm in labeling every image as suspicious or eliciting concern to avoid missing any important findings. 
Table 3. Knowledge, personal beliefs/attitudes, and practice attitudes.

\begin{tabular}{|c|c|c|c|c|c|}
\hline \multirow[t]{2}{*}{ Criteria } & \multicolumn{4}{|c|}{ Composite scores of correct answers } & \multirow[t]{2}{*}{$P$ value $^{\mathrm{a}}$} \\
\hline & Baseline & Posttest 1 & Posttest 2 & Posttest 3 & \\
\hline \multicolumn{6}{|l|}{ Knowledge } \\
\hline General skin cancer knowledge & 0.57 & 0.74 & 0.71 & 0.71 & $<.001$ \\
\hline $\mathrm{ABCDE}^{\mathrm{b}}$ knowledge & 0.64 & 0.68 & 0.68 & 0.83 & .002 \\
\hline Case-based image assessment & 0.74 & 0.72 & 0.72 & 0.72 & .04 \\
\hline \multicolumn{6}{|l|}{ Personal beliefs/attitudes } \\
\hline Prevention beliefs & 3.79 & 3.92 & 3.63 & 3.59 & $<.001$ \\
\hline Prevention behavior: $\mathrm{SSE}^{\mathrm{c}}$ & 2.97 & 3.23 & 3.42 & 3.53 & $<.001$ \\
\hline Prevention behaviors: clinical skin examination & 1.99 & 2.08 & 2.27 & 2.33 & $<.001$ \\
\hline Frequency of sun protection behavior & 3.73 & 3.82 & 3.84 & 3.84 & .03 \\
\hline General self-efficacy & 34.54 & 34.08 & 33.95 & 34.45 & .19 \\
\hline Perceived potential risk of skin cancer (on the scale of 1 to 100) & 44.54 & 43.29 & 39.46 & 40.91 & .10 \\
\hline \multicolumn{6}{|l|}{ Practice attitudes } \\
\hline Appropriateness of client interactions & 3.97 & 4.33 & 4.22 & 4.33 & $<.001$ \\
\hline Confidence in client interactions & 4.11 & 4.48 & 4.44 & 4.46 & $<.001$ \\
\hline Confidence in protecting one's own skin & 3.43 & 3.52 & 3.53 & 3.55 & .18 \\
\hline Confidence in assessing one's own skin & 3.34 & 3.5 & 3.48 & 3.51 & .08 \\
\hline
\end{tabular}

${ }^{\mathrm{a}}$ Statistical significance $(P<.05)$ for repeated measures analysis of variance.

${ }^{\mathrm{b}} \mathrm{ABCDE}$ : asymmetry, border, color, diameter, evolving.

${ }^{\mathrm{c}} \mathrm{SSE}$ : skin self-examination.

\section{Discussion}

\section{Feasibility}

The key finding was that the e-training was feasible and could be delivered online successfully. Similar to our pilot study [9], participants were highly satisfied with and accepting of the e-training. Clients were also satisfied with their MTs discussing skin cancer-prevention topics.

The main challenge was recruitment. Previous studies of MTs recruited participants attending massage therapy conferences $[15,29]$. To the best of our knowledge, this study was the first to recruit MTs for research from statewide independent, group, and national chain practices. Our initial multipronged recruitment efforts resulted in a surge of interested MTs that lasted 2 months. Contacts then lagged until we contacted the Arizona Chapter of the American Massage Therapy Association, purchased their mailing list, and mailed recruitment postcards to members as a secondary strategy. Contrary to previously reported observation of higher success with using social media versus direct mail to recruit hard-to-reach populations [30], the mailed postcard was the most effective recruitment strategy in our study. We did not ask participants why this strategy was successful but surmised that they preferred a direct outreach approach with targeted mailings [31] or did not tend to engage in social media.

Despite recruitment challenges, participants tended to stay in the study. According to the debriefing comments, once they completed the e-training, incentives such as continuing education credit and their own desire to add to the body of knowledge of their profession maintained their participation. This thinking reflected surveyed attitudes toward the e-training, with participants indicating that they would take the training without incentives and continuing education credit. This form of altruism is not unusual in community-based research, where participants desire to have a connection to science and their profession [32]. However, we would recommend incentives for future studies of this scope.

Collecting client survey responses was another challenge. MT participants received flyers that provided access to the client survey for posting in their practices; however, we had limited knowledge of whether they posted those flyers. We concur with others that flyers have limited utility [33]. At the 3- and 6-month evaluations, we asked MTs to remind clients about the survey, which appeared to improve the client survey response.

\section{Preliminary Efficacy}

The key finding was that participants' knowledge, personal behaviors (SSE, clinical skin examination, and frequency of sun protection), and practice attitudes (appropriateness and comfort with client-focused communication) of risk reduction for skin cancer improved and were sustained throughout the duration of the study. Despite these positive findings, there are some persistent issues.

Improved skin cancer knowledge is consistent with findings of previous education interventions for skin cancer provided to 
MTs or cosmetologists [29,34]. Although knowledge improved, it improved to a barely "passing score," which reflected the passing score $(70 \%)$ required for the Massage \& Bodywork Licensing Examination (MBLEx) [35]. The most common incorrect knowledge answers selected at 6 months were the strongest risk factor for melanoma, indices important for reducing exposure to ultraviolet radiation, and recommended sunscreen ingredients. We are considering adding "boosters" to the revised e-training to further improve knowledge that is critical to helping conversations.

Attitudes favorably increased over the duration of the intervention except for self-efficacy and perceived risk of skin cancer. The general self-efficacy scale reflects a belief that an individual is capable of performing novel or difficult tasks and coping with adversity [27]. Self-efficacy scores did not significantly change over the 3 data collection points. Although participants had positive general self-efficacy, they were neutral in their confidence for protecting and assessing their own skin. They were more comfortable discussing skin cancer risk reduction with their clients, which reflects findings from other studies [15]. A situation-specific self-efficacy measure may be more useful in characterizing MTs' self-confidence, particularly that of helping conversations. A perceived risk of skin cancer is most commonly considered a stable belief; however, it could change under specific circumstances, such as a personal skin cancer diagnosis [36].

\section{Exploratory Aim: Case-Based Image Assessment}

We explored whether participants could assess a suspicious versus nonsuspicious skin lesion using the ABCDE rule. Although participants' understanding of the rule improved over time, mean correct scores on the case-based image assessment at all time points fell in the range of $72 \%-74 \%$. Trotter et al [29] had a similar finding in their image assessment using just 4 images. Participants in our study tended to correctly score "ugly duckling" (unsightly) lesions and incorrectly score nonsuspicious lesions. This pattern has been reported in other studies of case-based image assessments [29]. The drop in scores following the training may be attributable to MTs' opinions mentioned during the debriefing session, where they would "rather be safe than sorry" and were likely to select all images as suspicious and warranting referral. Throughout the study, MTs shared their desire for more images of skin cancers as well as the correct answers to the image assessment. Although the latter was not feasible as per the study design, future e-training content will use a larger image bank that will enable us to alternate image choices during data collection and provide immediate feedback.

\section{Additional Limitations}

There is some missing data in our analysis due to our failure to initially force item responses and initially develop asynchronous/chained survey invitations when designing the online instruments. We added questions (MT practice type and asking for more specific training feedback) shortly after the enrollment began, further resulting in missing data from the previous version. In total, 3 participants failed to fully complete a total of 7 surveys between them. Our Arizona-specific sample also limits generalizability to MTs in other geographic areas. The heterogeneity of MT practice models (eg, sole proprietor, employee, partner, and independent contractor) made it challenging to recruit participants and collect data for client surveys. Noninclusion of a control group limits the strength of our findings and will be incorporated in future research.

\section{Conclusions}

Our results demonstrated that it is possible to engage practicing MTs in a skin cancer education study and that MTs will complete e-training. We also demonstrated that although MTs completed 2-hour-long, case-based e-training, it was not sufficient to significantly increase their self-efficacy in initiating helping conversations about skin cancer with clients or their ability to recognize images of skin cancers. The e-training increased their knowledge about skin cancer prevention and early detection.

\section{Acknowledgments}

The study was funded by the Arizona Biomedical Research Centre (Grant 16-162518). Services and products used in the research project were generated by the University of Arizona Cancer Center Behavioral Measurement and Interventions Shared Resource and were partly supported by an NIH-NCI Cancer Center Support Grant (P30 CA023074).

\section{Conflicts of Interest}

None declared.

\section{References}

1. Rogers HW, Weinstock MA, Feldman SR, Coldiron BM. Incidence Estimate of Nonmelanoma Skin Cancer (Keratinocyte Carcinomas) in the U.S. Population, 2012. JAMA Dermatol 2015 Oct;151(10):1081-1086. [doi:

10.1001/jamadermatol.2015.1187] [Medline: 25928283]

2. American Cancer Society. Cancer facts and figures. Atlanta: American Cancer Society; 2020. URL: https://www.cancer.org/ content/dam/cancer-org/research/cancer-facts-and-statistics/annual-cancer-facts-and-figures/2020/ cancer-facts-and-figures-2020.pdf [accessed 2020-05-05]

3. Guy GJ, Machlin S, Ekwueme D, Yabroff K. Prevalence and costs of skin cancer treatment in the U.S., 2002-2006 and 2007-2011. Am J Prev Med 2015 Feb;48(2):183-187 [FREE Full text] [doi: 10.1016/j.amepre.2014.08.036] [Medline: 25442229] 
4. International Agency for Research on Cancer (IARC) working group on the evaluation of carcinogenic risks to humans. Solar and ultraviolet radiation. In: IARC Monographs on the Evaluation of Carcinogenic Risks to Humans. Lyon: International Agency of Research on Cancer, World Health Organization; 1992.

5. Colantonio S, Bracken MB, Beecker J. The association of indoor tanning and melanoma in adults: systematic review and meta-analysis. J Am Acad Dermatol 2014 May;70(5):847-57.e1. [doi: 10.1016/j.jaad.2013.11.050] [Medline: 24629998]

6. The Surgeon General's Call to Action to Prevent Skin Cancer. US Department of Health and Human Services. Washington, DC; 2014. URL: https://www.hhs.gov/sites/default/files/call-to-action-prevent-skin-cancer.pdf [accessed 2017-10-10]

7. American Academy of Dermatology Ad Hoc Task Force for the ABCDEs of Melanoma, Tsao H, Olazagasti JM, Cordoro KM, Brewer JD, Taylor SC, et al. Early detection of melanoma: reviewing the ABCDEs. J Am Acad Dermatol 2015 Apr;72(4):717-723. [doi: 10.1016/j.jaad.2015.01.025] [Medline: 25698455]

8. Muramoto ML, Matthews E, Ritenbaugh CK, Nichter MA. Intervention development for integration of conventional tobacco cessation interventions into routine CAM practice. BMC Complement Altern Med 2015 Mar 29;15(1):96 [FREE Full text] [doi: 10.1186/s12906-015-0604-9] [Medline: 25887742]

9. Loescher LJ, Heslin KM, Szalacha LA, Silva GE, Muramoto ML. Web-Based Skin Cancer Prevention Training for Massage Therapists: Protocol for the Massage Therapists Skin Health Awareness, Referral, and Education Study. JMIR Res Protoc 2019 May 15;8(5):e13480 [FREE Full text] [doi: 10.2196/13480] [Medline: 31094348]

10. Muramoto ML, Howerter A, Eaves ER, Hall JR, Buller DB, Gordon JS. Online Tobacco Cessation Training and Competency Assessment for Complementary and Alternative Medicine (CAM) Practitioners: Protocol for the CAM Reach Web Study. JMIR Res Protoc 2016 Jan 06;5(1):e2 [FREE Full text] [doi: 10.2196/resprot.5061] [Medline: 26740468]

11. Nahin RL, Barnes PM, Stussman BJ, Bloom B. Costs of complementary and alternative medicine (CAM) and frequency of visits to CAM practitioners: United States, 2007. Natl Health Stat Report 2009 Jul 30(18):1-14 [FREE Full text] [Medline: 19771719]

12. Cherkin DC, Deyo RA, Sherman KJ, Hart LG, Street JH, Hrbek A, et al. Characteristics of visits to licensed acupuncturists, chiropractors, massage therapists, and naturopathic physicians. J Am Board Fam Pract 2002;15(6):463-472. [Medline: 12463292]

13. Heiligers PJ, de Groot J, Koster D, van Dulmen S. Diagnoses and visit length in complementary and mainstream medicine. BMC Complement Altern Med 2010 Jan 25;10:3 [FREE Full text] [doi: 10.1186/1472-6882-10-3] [Medline: 20100343]

14. Massage Therapy Industry Fact Sheet 2019. American Massage Therapy Association. 2020. URL: https://www. amtamassage.org/globalassets/documents/src/2019-pdf.pdf

15. Campbell SM, Louie-Gao Q, Hession ML, Bailey E, Geller AC, Cummins D. Skin cancer education among massage therapists: a survey at the 2010 meeting of the American Massage Therapy Association. J Cancer Educ 2013 Mar;28(1):158-164. [doi: 10.1007/s13187-012-0403-7] [Medline: 22915212]

16. Neufeld A, Anderson S. Massage therapists and the detection of skin cancer in clients. Massage Today. 2013 Feb. URL: https://www.massagetoday.com/articles/14711/Massage-Therapists-and-the-Detection-of-Skin-Cancer-in-Clients [accessed 2020-10-26]

17. LaPlante C. First line of defense: Early detection of skin cancer by massage therapists can save lives. Massage Therapy Journal 2008 Mar 22;47(1):90.

18. Bandura A. Health promotion by social cognitive means. Health Educ Behav 2004 Apr;31(2):143-164. [doi: 10.1177/1090198104263660] [Medline: 15090118 ]

19. Julious SA. Sample size of 12 per group rule of thumb for a pilot study. Pharmaceut. Statist 2005 Oct;4(4):287-291. [doi: $10.1002 /$ pst.185]

20. Cliff S, Bedlow A, Melia J, Moss S, Harland C. Impact of skin cancer education on medical students' diagnostic skills. Clin Exp Dermatol 2003 Mar;28(2):214-217. [doi: 10.1046/j.1365-2230.2003.01237.x] [Medline: 12653717]

21. Tyler-Smith K. Early Attrition among First Time eLearners: A Review of Factors that Contribute to Drop-out, Withdrawal and Non-completion Rates of Adult Learners undertaking eLearning Programmes. J Online Learn Teach 2006;2(2).

22. PASS 2020. NCSS Statistical Software. Kaysville, Utah, USA: NCSS, LLC; 2020. URL: https://www.ncss.com/software/ pass/ [accessed 2020-05-05]

23. Davis R, Loescher LJ, Rogers J, Spartonos D, Snyder A, Koch S, et al. Evaluation of Project Students are Sun Safe (SASS): A University Student-Delivered Skin Cancer Prevention Program for Schools. J Cancer Educ 2015 Dec 25;30(4):736-742. [doi: 10.1007/s13187-014-0742-7] [Medline: 25417824]

24. Harris PA, Taylor R, Thielke R, Payne J, Gonzalez N, Conde JG. Research electronic data capture (REDCap)--a metadata-driven methodology and workflow process for providing translational research informatics support. J Biomed Inform 2009 Apr;42(2):377-381 [FREE Full text] [doi: 10.1016/j.jbi.2008.08.010] [Medline: 18929686]

25. Harris PA, Taylor R, Minor BL, Elliott V, Fernandez M, O'Neal L, REDCap Consortium. The REDCap consortium: Building an international community of software platform partners. J Biomed Inform 2019 Jul;95:103208 [FREE Full text] [doi: 10.1016/j.jbi.2019.103208] [Medline: 31078660]

26. Loescher LJ, Howerter AL, Heslin KM, Azzolina CM, Muramoto ML. A Survey of Licensed Massage Therapists' Perceptions of Skin Cancer Prevention and Detection Activities. Int J Ther Massage Bodywork 2018 Dec;11(4):4-10 [FREE Full text] [Medline: 30524632] 
27. Schwarzer R, Jerusalem M. Generalized Self-Efficacy Scale. In: Measures in Health Psychology: A User's Portfolio. Windsor, England: NFER-NELSON; 1995.

28. Harris JM, Salasche SJ, Harris RB. Can Internet-based continuing medical education improve physicians' skin cancer knowledge and skills? J Gen Intern Med 2001 Jan;16(1):50-56. [Medline: 11251750]

29. Trotter SC, Louie-Gao Q, Hession MT, Cummins D. Skin cancer education for massage therapists: a novel approach to the early detection of suspicious lesions. J Cancer Educ 2014 Jun;29(2):266-269. [doi: 10.1007/s13187-013-0589-3] [Medline: 24407881]

30. Cowie JM, Gurney ME. The Use of Facebook Advertising to Recruit Healthy Elderly People for a Clinical Trial: Baseline Metrics. JMIR Res Protoc 2018 Jan 24;7(1):e20 [FREE Full text] [doi: 10.2196/resprot.7918] [Medline: 29367186]

31. Kaar JL, Markovic N, Amsden LB, Gilliland J, Shorter CF, Peters B, et al. The Experience of Direct Outreach Recruitment in the National Childrens Study. PEDIATRICS 2016 Jun 01;137(Supplement):S258-S264. [doi: 10.1542/peds.2015-4410g]

32. Carrera JS, Brown P, Brody JG, Morello-Frosch R. Research altruism as motivation for participation in community-centered environmental health research. Soc Sci Med 2018 Jan;196:175-181 [FREE Full text] [doi: 10.1016/j.socscimed.2017.11.028] [Medline: 29190538]

33. Mendez-Luck CA, Trejo L, Miranda J, Jimenez E, Quiter ES, Mangione CM. Recruitment strategies and costs associated with community-based research in a Mexican-origin population. Gerontologist 2011 Jun;51 Suppl 1:S94-105 [FREE Full text] [doi: 10.1093/geront/gnq076] [Medline: 21565824]

34. Radisic A, Hundley K, Patel N, Nelson C, Mhaskar R. Assessment of impact of a skin cancer education session on cosmetology students' knowledge and preparedness to assess future clients for skin lesions. J Cosmet Dermatol 2020 Jan;19(1):205-210. [doi: 10.1111/jocd.12996] [Medline: 31081582]

35. Massage and Bodywork Licensing Examination. Federation of State Massage Therapy Boards. 2020. URL: https://www. fsmtb.org/mblex/ [accessed 2020-05-05]

36. Schildberg-Hörisch H. Are Risk Preferences Stable? Journal of Economic Perspectives 2018 May 01;32(2):135-154. [doi: 10.1257/jep.32.2.135]

\author{
Abbreviations \\ ABCDE: asymmetry, border, color, diameter, evolving \\ e-training: electronic training \\ MBLEx: Massage \& Bodywork Licensing Examination \\ MT: massaging therapist \\ QR: quick response \\ SCT: social cognitive theory \\ SSE: skin self-examination \\ VSA: viewable skin assessment
}

Edited by G Eysenbach; submitted 10.06.20; peer-reviewed by J Makin, A Reeder; comments to author 09.07.20; revised version
received 15.07.20; accepted 02.10.20; published 02.11.20
Please cite as:
Loescher L, Heslin K, Silva G, Muramoto M
Partnering With Massage Therapists to Communicate Information on Reducing the Risk of Skin Cancer Among Clients: Longitudinal
Study
JMIR Form Res 2020;4(11):e21309
URL: $\underline{\text { https://formative.jmir.org/2020/11/e21309 }}$
doi: $10.2196 / 21309$
PMID: $\underline{33136054}$

CLois Loescher, Kelly Heslin, Graciela Silva, Myra Muramoto. Originally published in JMIR Formative Research (http://formative.jmir.org), 02.11.2020. This is an open-access article distributed under the terms of the Creative Commons Attribution License (https://creativecommons.org/licenses/by/4.0/), which permits unrestricted use, distribution, and reproduction in any medium, provided the original work, first published in JMIR Formative Research, is properly cited. The complete bibliographic information, a link to the original publication on http://formative.jmir.org, as well as this copyright and license information must be included. 